\title{
Design and experiment of bionic stubble breaking-deep loosening combined tillage machine
}

\author{
Jiale Zhao ${ }^{1,2}$, Yun $\mathrm{Lu}^{1}$, Mingzhuo Guo ${ }^{1}$, J un Fu' ${ }^{1,2}$, Yijia Wang ${ }^{3 *}$ \\ (1. College of Biological and Agricultural Engineering, Jilin University, Changchun 130025, China; \\ 2. Key Laboratory of Bionics Engineering, Ministry of Education, Jilin University, Changchun 130025, China; \\ 3. Department of Industrial and Manufacturing Systems Engineering, The University of Hong Kong, Pokfulam Road, Hong Kong, China)
}

\begin{abstract}
Under the conditions of straw returning operation, there are three major technical bottlenecks in the Phaeozem region of northeast China, namely low stubble breaking rate, poor tillage depth consistency, and high fuel consumption. In this research, a bionic stubble-deep loosening combined tillage machine (BSD) was designed through bionic prototype analysis, coupled bionic analysis, coupled bionic design, theoretical analysis and application of intelligent control techniques. It consists of a bionic stubble breaking device and a bionic self-excited vibratory deep loosening device. Based on the unique biting pattern of locust mouthparts on maize rootstocks, the bionic stubble breaking device adopted a new multi-segment serrated bionic structure and a symmetrical rotational motion, which could significantly increase the stubble breaking rate $(p<0.05)$ and reduce the resistance to stubble breaking operations $(p<0.05)$. Based on the unique biology of the hare's paws, toes and nails, the bionic self-excited vibration deep loosening device adopted a new series-parallel composite bionic elastic system and an intelligent tilling depth control system with a fuzzy algorithm, which significantly improved the tilling depth consistency $(p<0.05)$. The operational performance of the BSD was verified at different operating speeds through comparative experiments and reveals the mechanism of its excellent performance through theoretical analysis. The final experiment results showed that, at the same operating speed, the BSD improved the stubble breaking rate by $9.62 \%$ and $10.67 \%$, reduced the stubble breaking torque by $28 \mathrm{~N} \cdot \mathrm{m}$ and $33 \mathrm{~N} \cdot \mathrm{m}$, reduced the tillage depth coefficient of variation by $12.73 \%$ and $13.48 \%$, and reduced the specific fuel consumption by $36 \mathrm{~g} / \mathrm{km} \cdot \mathrm{h}$ and $40 \mathrm{~g} / \mathrm{km} \cdot \mathrm{h}$ compared to the two most common models. The operating performance of the three kinds of machines will decrease with the increase of operating speed, and the BSD has the least decrease.
\end{abstract}

Keywords: bionics, stubble breaking, deep loosening, combined tillage machine DOI: $10.25165 /$ j.ijabe.20211404.6473

Citation: Zhao J L, Lu Y, Guo M Z, Fu J, Wang Y J. Design and experiment of bionic stubble breaking-deep loosening combined tillage machine. Int J Agric \& Biol Eng, 2021; 14(4): 123-134.

\section{Introduction}

The promotion of conservation tillage technology relies on high-performance implements ${ }^{[1]}$. The performance requirements for conservation tillage implements vary considerably from one planting area to another. The Phaeozem region of northeast China is the most important commercial grain base in China ${ }^{[2]}$, which is known as the golden maize belt ${ }^{[3]}$. The unique climate and planting characteristics of this planting area have led to three major technical problems in the operation of existing stubble-deep loosening combined tillage machine in the maize planting areas ${ }^{[4,5]}$, i.e., 1) Low stubble breaking rate: The maize rhizomes in this planting area are strong and the moisture content is high, which makes the resistance of stubble breaking operation far greater than other areas ${ }^{[6]}$; 2) Poor consistency of tilling depth in deep loosening operation: severe soil consolidation in this growing area is

Received date: 2021-01-21 Accepted date: 2021-06-14

Biographies: Jiale Zhao, $\mathrm{PhD}$, Associate Professor, research interest: conservation tillage, Email: zhaojiale0313@163.com; Yun Lu, PhD candidate, research interest: conservation tillage, Email: 83603557@163.com; Mingzhuo Guo, $\mathrm{PhD}$, Lecturer, research interest: conservation tillage, Email: guomingzhuo@outlook.com; Jun Fu, PhD, Professor, research interest: maize harvesting, Email: fu_jun@jlu.edu.cn.

*Corresponding author: Yijia Wang, Postdoctoral, research interest: applications of machine learning and optimization theory in smart agriculture. Department of Industrial and Manufacturing Systems Engineering, The University of Hong Kong, Pokfulam Road, Hong Kong, China. Tel: +861662974902, Email: yijiawang@connect.hku.hk. associated with a high level of straw cover ${ }^{[7-10]}$, which makes it difficult to guarantee the consistency of tilling depth ${ }^{[11,12]}$; 3) High fuel consumption for stubble-deep loosening combined tillage machine: the soil in this planting area has strong cohesion and high adhesion $^{[13]}$, and the amount of rootstock returned to the field is much larger than that in other areas, resulting in high energy consumption for combined operation ${ }^{[14]}$.

In recent years, bionic design methods have become a source of creativity in solving engineering challenges due to their ability to replicate superior biological functions onto engineering equipment ${ }^{[15-19]}$. Recent biological discoveries have shown that locust mouthparts act like highly efficient blades for cutting crop roots $^{[20,21]}$. Its gnawing energy consumption is only $67 \%$ of that of existing stubble cutting tools ${ }^{[22]}$ and its gnawing cut-off rate is nearly $100 \%{ }^{[23,24]}$. The proverb "the smart rabbit can dig the most holes" illustrates the hare's great ability to dig into the soil and its energy consumption for cutting the soil is only $88 \%$ of that of existing tillage components ${ }^{[25,26]}$. At the same time, the hare's nest has extremely smooth walls ${ }^{[27]}$, which means that it has very precise control over its digging movements ${ }^{[28]}$. It can be seen that the engineering design reproduces the excellent functions of the locust mouthparts and hare's claw toe, allowing for efficient stubble breaking, low consumption, and precise control of the tilling depth at the same time.

In this study, a multi-coupled bionic design approach was proposed to develop a bionic stubble breaking device based on locust mouthparts and a bionic self-excited vibrating deep 
loosening device based on hare paw toes and to design the bionic stubble breaking-deep loosening combined tillage machine (BSD) by integrating the above devices. At the same time, through comparative experiments and theoretical analysis, the mechanism of the effect of bionic design on stubble breaking rate, tillage depth consistency, and specific fuel consumption was explored. The findings of the study are expected to provide support for equipment and technology to promote the extension of conservation tillage technology in the phaeozem region of northeast China.

\section{Design of the bionic stubble-deep loosening combined tillage machine}

\subsection{Design of the bionic stubble breaking device}

\subsubsection{Bionic prototype analysis}

The locust mouthpiece differs significantly in its structural form and mode of movement compared to existing stubble-breaking mechanisms. As shown in Figure 1, the blade of existing stubble-breaking blades is generally a smooth curve, while the locust mouthpiece has a segmented serrated structure. The segmented serration structure makes it easier to pierce the outer skin of the maize rootstock and thus easier to cut the rootstock. The movement of the existing stubble-breaking tool is unidirectional rotation, and the locust mouthpiece is symmetrical rotation. The symmetrical rotation can serve to hold the rootstock in place and effectively reduce the energy consumption caused by rootstock slippage. In this paper, based on the uniqueness of the locust mouthpiece in terms of structure and motion coupling elements, the coupled bionic design of the stubble breaking mechanism is carried out.

\subsubsection{Bionic stubble-breaking blade}

The profilogram of Figure 2 was processed in Matlab software using the rgb2gray, imerode, imdilate, im2bw, Imfill, and edge function commands, respectively, to convert the locust mouthparts from the original image to a binary image and to derive the curve contour coordinate points. Finally, the LOG algorithm was used to plot the coordinate points into a final boundary map, and the entire profilogram was divided into 5 parts, each wave crest is a unit, connected by a first and last link.

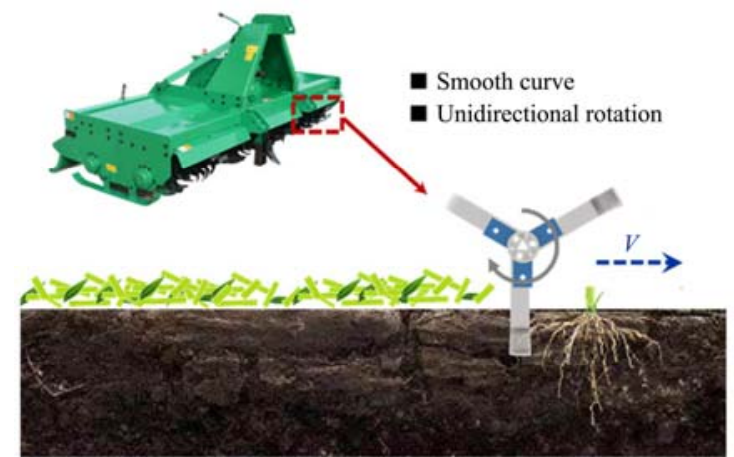

a. Stubble cutter

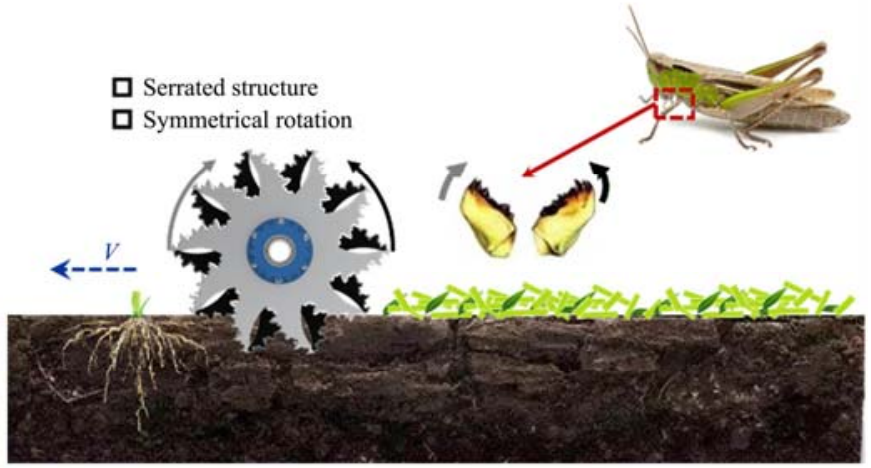

b. Bionic stubble-clean devive

Figure 1 Diagram of the locust mouthpiece compared to existing stubble breaking mechanisms

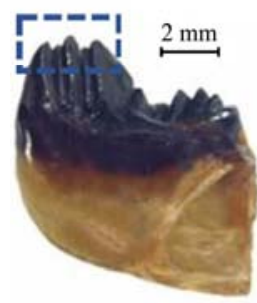

a. Original image

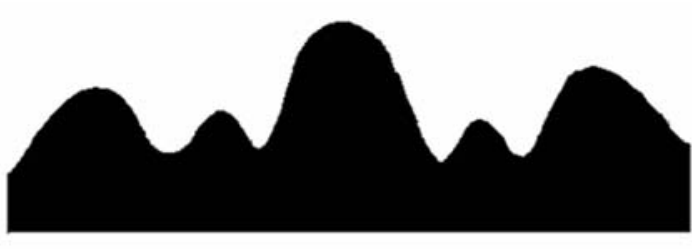

b. Binary image

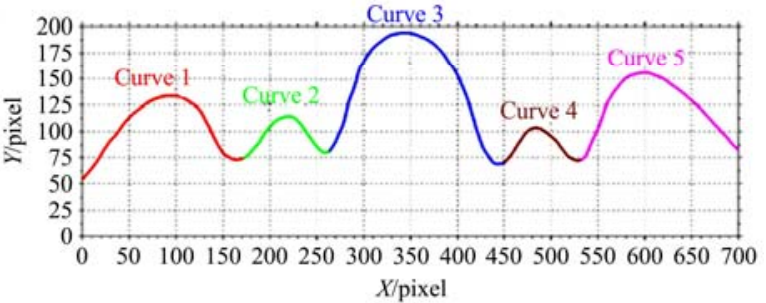

c. Boundary image

Figure 2 Extraction of the profilogram of the locust mouthparts

Using Origin software and the Polynomial Fit command to fit each of the five curves on the cutting edge of the mouthpiece, the least-squares method was applied to obtain Equation (1) for the fitting of the cutting edge curve of the locust mouthpiece, and the fitted variance of all five curves was found to be greater than 0.99 by Matlab.

$$
\varphi\left(x_{i}\right)=\left[\begin{array}{llll}
55.397 & 0.458 & 0.066 & -0.002 \\
74.711 & 0.3398 & 0.062 & -0.002 \\
82.311 & 0.203 & 0.183 & -0.005 \\
70.575 & 0.313 & 0.126 & -0.006 \\
72.463 & 0.672 & 0.118 & -0.004
\end{array}\right] \times\left[\begin{array}{c}
1 \\
x \\
x^{2} \\
x^{3} \\
x^{4}
\end{array}\right]
$$

where, $\varphi\left(x_{i}\right)$ represents the equation of the five-segment affine curve; $x_{i}$ represents the horizontal coordinates of the points on the curve, $\mathrm{mm}$.

As shown in Figure 3, the design of the bionic stubble-breaking blade curve by means of isometric enlargement and multi-stage curve connected at the first place, highly reproducing the structure of the locust's mouthparts. The relationship between the key design parameters of the bionic stubble-breaking blade should satisfy Equation (2). Studies showed that the optimum rotation radius $D$ for maize stubble breaking in the phaeozem region of northeast China should be $500 \mathrm{~mm}^{[29-33]}$ and the individual blade height $H$ should be $125 \mathrm{~mm}^{[34]}$. At the same time, the shorter the blade curve, the smaller the sliding distance and the lower the power consumption under the same conditions of working depth and rotation radius. In summary, it can be concluded that the design of each parameter of the bionic chopper cutter is shown in Figure 3.

$$
\left\{\begin{array}{l}
L=n k \int_{x_{\min }}^{x_{\max }} \sqrt{1+\varphi^{2}(x)} \mathrm{d} x \\
\left(x_{\max }-x_{\min }\right) n k=H=(D-d) / 2 \\
\varphi\left(x_{\max }\right)-\varphi\left(x_{\min }\right)=\widehat{l}_{A B} / n k=2 \pi d / N n k
\end{array}\right.
$$




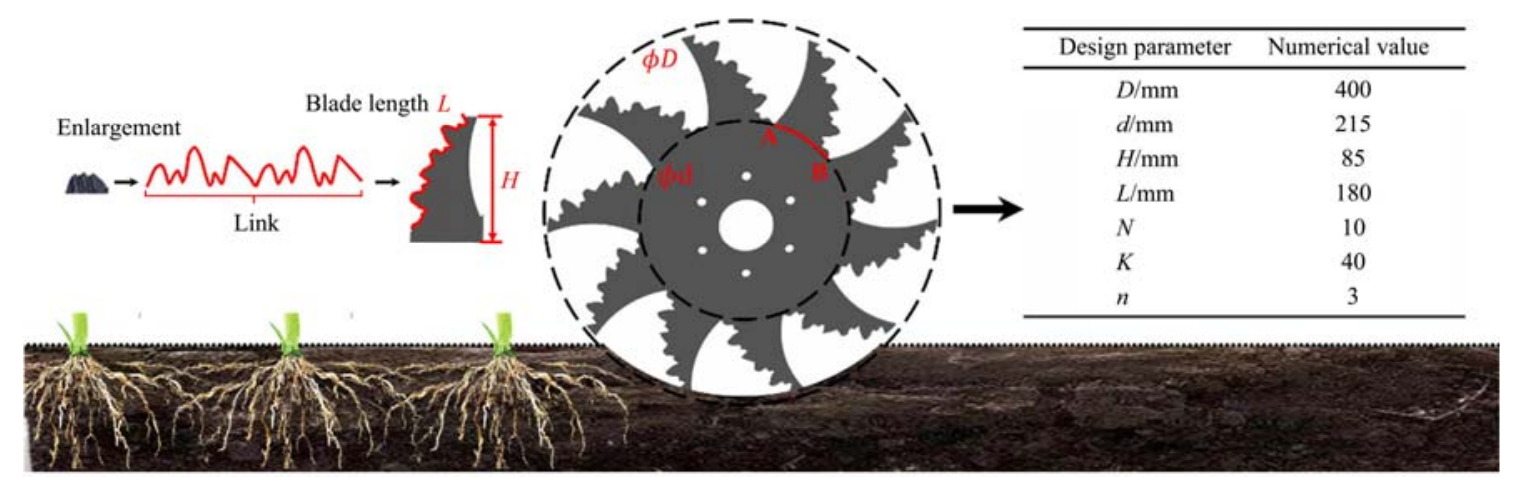

Note: $D$ is the rotation radius; $d$ is inner disc diameter; $H$ is the height of individual blade; $L$ is the blade length; $N$ is the number of blades; $K$ is the isometric amplification factor; $n$ is the number of repetitions of the bionic blade curve.

Figure 3 Structure of the locust's mouthparts

\subsubsection{Bionic drive system}

As shown in Figure 4, the bionic drive system consists of a gearbox, a forward stubble-breaking blade drive system, a reverse stubble-breaking blade drive system, and a stubble-breaking blade speed intelligent control system. The gearbox can output both forward and reverse torque during operation as shown in Figure 4. The forward drive system transmits the forward torque to the forward stubble-breaking blade via the chain drive; The reversing drive system transmits the reversing torque to the reversing stubble-breaking blade via the chain drive; The reversing blade shaft, the chain drive, and the reversing sprocket. As shown in Figure 4, the reversing stubble-breaking blade is fixed to the reversing sprocket, which is connected to the forward blade shaft via a bearing, so that the reversing stubble-breaking blade is not affected by the forward blade shaft. The stubble breaking mechanism is generally set at a single row width of $180-200 \mathrm{~mm}^{[35]}$, so every two bionic stubble blades are set at a distance of $65 \mathrm{~mm}$. Every two forward and reverse bionic stubble blades break a monopoly of maize stubble during operation.

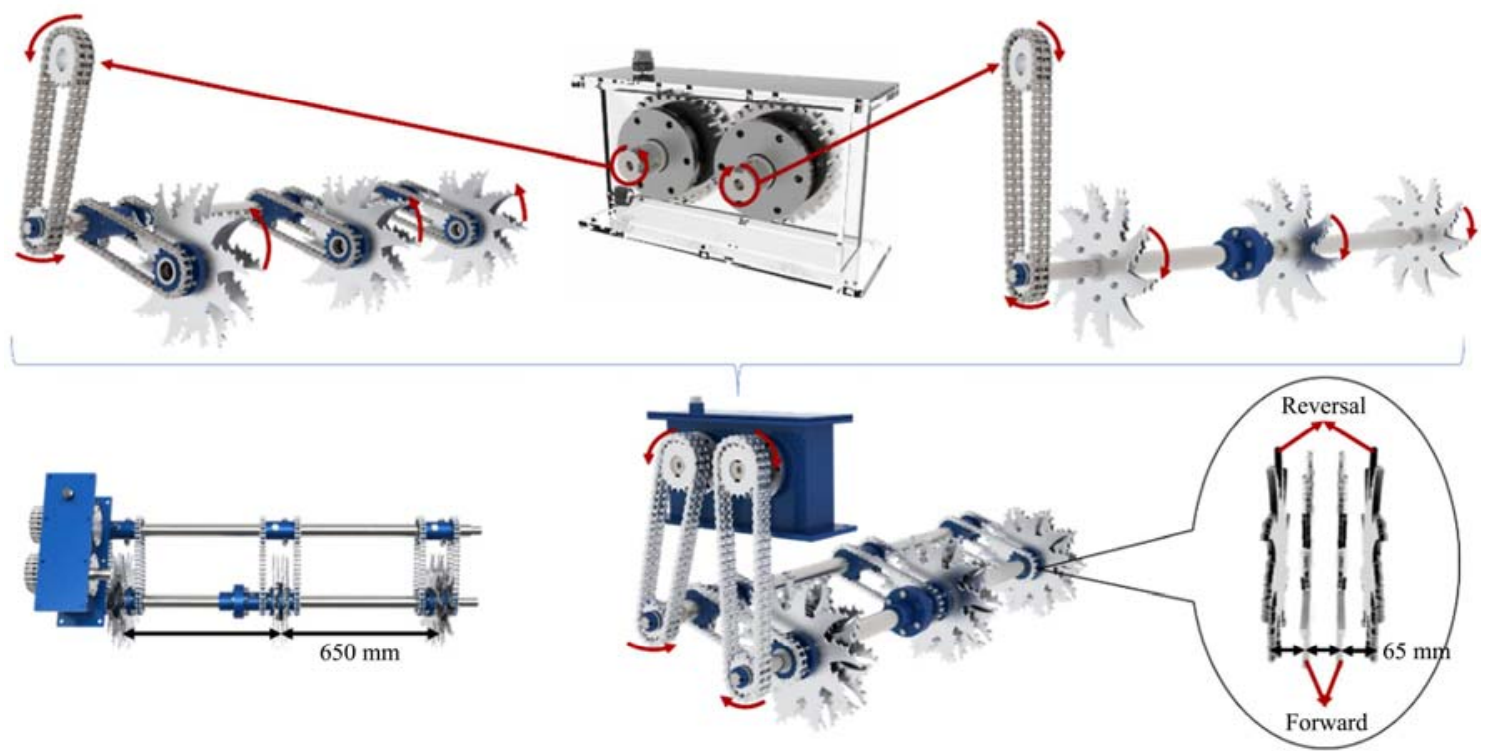

Figure 4 Schematic diagram of the bionic drive system

\subsection{Bionic self-excited vibration deep loosening device}

\subsubsection{Bionic prototype analysis}

The hare's efficient soil digging ability is due to the unique claw toes and nails it has evolved. Each toe consists of three joints, two phalanges, and ligaments. The ligaments and joints are elastic tissues that provide elasticity and store elastic potential energy. The phalanges are the rigid tissues that connect and support the entire paw toe. Each toe can be considered as a rigid-flexible elastic system, with multiple elastic tissues acting as resistance reduction by vibration, restorers, and energy stores. At the same time, the ligaments adjust the overall elastic modulus of the paw toe in response to changes in soil strength, enabling precise control of digging depth. The main role of the hare's nails is to cut the soil, and they have evolved a unique curved structure that can significantly reduce soil digging resistance. In this paper, a bionic design of a vibratory bionic self-excited vibratory deep loosening device is developed using the hare's claw toes and nail as a bionic prototype.

2.2.2 Bionic self-excited vibration deep loosening mechanism

(1) Bionic deep loosening shovel

The bionic deep loosening mechanism consists of a bionic deep loosening shovel and a bionic elastic system. In this study, the bionic design of the shovel is based on the structural characteristics of the hare's nails. As shown in Figure 5b, the inner and outer profilogram of the hare's nails were extracted by Matlab through image processing, from which the curves of the bionic deep loosening shovel blade and the shovel bottom were obtained as:

$$
\begin{aligned}
& Y_{1}=4.52-7.31 e^{-X_{1} / 1.98} \\
& Y_{2}=4.68-16.94 e^{-X_{2} / 2.47}
\end{aligned}
$$

The reciprocating motion of the self-excited vibration deep loosening shovel under soil resistance produces huge energy 
consumption. The relationship among the blade width $a$, height $H_{3}$, structural angle $\beta_{3}$, deflection radius $L_{3}$ and reciprocating motion energy consumption $Q_{3}$ of the bionic deep loosening shovel satisfies Equation (4) ${ }^{[36]}$. It can be seen that the length $L_{3}$ of the bionic shovel is proportional to the energy consumption $Q_{3}$ of the reciprocating movement. Meanwhile, in order to guarantee the trafficability of the deep loosening shovel, the bionic elastic system should have a height $H$ of more than $50 \mathrm{~mm}$, and the operating depth $h$ is $400 \mathrm{~mm}$. In summary, it is concluded that the height $H_{3}$ of the bionic deep loosening shovel should be chosen as $450 \mathrm{~mm}$.
The measured height of the hare's nail is $20 \mathrm{~mm}$, the width is $1 \mathrm{~mm}$, and the structural deflection angle is $50^{\circ}$. The width of blade $a$ of the bionic deep loose shovel should be $22.5 \mathrm{~mm}$, and the height $\mathrm{H}_{3}$ is $450 \mathrm{~mm}$ while the structural deflection angle is $50^{\circ}$ and the deflection radius $L_{3}$ is $600 \mathrm{~mm}$.

$$
\left[\begin{array}{c}
L_{3} \sin \beta_{3}=H_{3} \\
H_{3} \geq H+h \\
Q_{3}=\int_{0}^{h} \int_{0}^{\frac{\alpha \pi L_{3}}{180}}(c+\sigma \tan \varphi) a \mathrm{~d} h \mathrm{~d} L_{3}
\end{array}\right]
$$

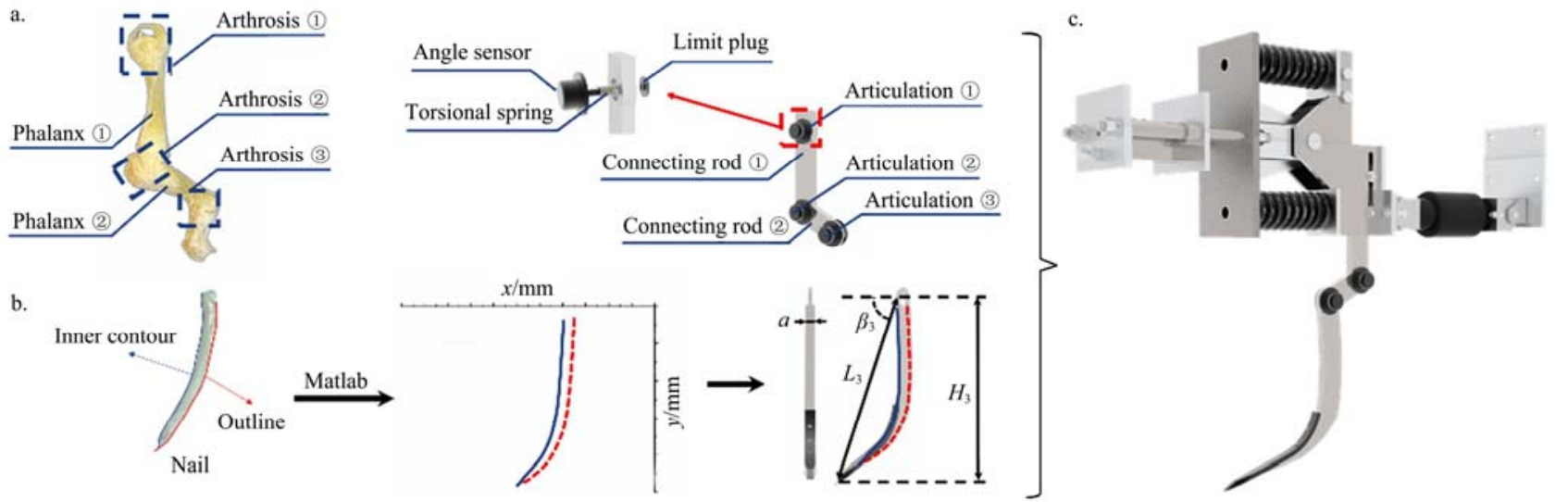

Figure 5 Diagram of the structure of the bionic self-excited vibration deep loosening mechanism

(2) Bionic elastic system

As shown in Figure 5c, the bionic elastic system consists of a bionic tandem-parallel composite elastic system with an intelligent tillage depth control system. The bionic resilient system consists of three resilient hinges and two connecting rods. Each elastic hinge system consists of a torque spring, an angle sensor, and a positioning pin. The articulation (1) and the articulation (2) form a parallel elastic system (1) with the connecting rod A as a rigid carrier (1) and (2) and (3) in the text corresponds to the criteria in Figure 5). The articulation (2) and the articulation (3) form a parallel elastic system (2) with the connecting $\operatorname{rod} \mathrm{B}$ as a rigid carrier. The two parallel elastic systems are connected in series by the articulation (2) to form a series-parallel compound elastic system. Due to the dynamic balance, the two hinges of the parallel elastic system rotate in opposite directions. When the force on the shovel changes, the shovel can be self-excited by hinges (1) and (3), while the reverse rotation of hinge (2) reduces the amplitude generated by the self-excited vibration of the shovel. However, the parallel design of the torque springs reduces the overall equivalent modulus of elasticity of the system and increases the vibration amplitude of the shovel. Therefore, two parallel elastic systems are connected in series by articulation (2) to form a series-parallel composite elastic system, which corrects the overall equivalent modulus of elasticity of the system. The equivalent modulus of elasticity of the bionic elastic system $k^{\prime}$, and the physical parameters of the soil satisfy Equation (5).

$$
\left[\begin{array}{l}
k^{\prime}=\frac{k_{1} k_{2}\left(k_{2}+k_{3}\right)+k_{2} k_{3}\left(k_{1}+k_{2}\right)}{\left(k_{1}+k_{2}\right)\left(k_{2}+k_{3}\right)} \\
k^{\prime} \alpha_{\max }^{\prime}=F-\int_{0}^{h}(c+\sigma \tan \varphi) a \mathrm{~d} h
\end{array}\right]
$$

where, $k_{1}, k_{2}$, and $k_{3}$ are the elastic coefficient of torque spring, $\mathrm{N} / \mathrm{m}$; $k^{\prime}$ is the equivalent elastic coefficient of torque spring; $\alpha_{\text {max }}^{\prime}$ is the maximum angle of equivalent deformation, $\left({ }^{\circ}\right) ; c$ is the soil cohesion, $\mathrm{N} ; \varphi$ is the soil friction angle, $\left({ }^{\circ}\right) ; \sigma$ is pressure, $\mathrm{Pa} ; a$ is the width of the blade, $\mathrm{m} ; h$ is the depth of the blade into the soil, $\mathrm{m}$.
The soil data of Changchun, Jilin Province, was selected as the design background. Its soil is black clay with the soil cohesion is $49 \mathrm{kPa}^{[37,38]}$ and the soil internal friction angle is $32.6^{\circ[39]}$. The weight of the BSD is $1500 \mathrm{~kg}$, and the maximum permissible deflection angle of the deep loosening shovel is $23.6^{\circ[40]}$. In order to meet the interchangeability between the various parts of the machine and ensure the balance of forces between the connecting rods, the same torque spring parameters are used for the articulation (1), (2), and (3). According to Equation (6), the design parameters of the torque spring selected for each articulation are shown in Table 1.

$$
\left\{\begin{array}{l}
D=C \cdot d \\
n=\frac{E d^{4} \varphi}{3667 D\left(T_{n}-T_{1}\right)} \\
T=\frac{E d^{4}}{3667 D n} \\
t=d+\delta \\
H_{0}=n t+d \\
\alpha=\arctan \frac{t}{\pi D} \\
L_{s}=\frac{\pi D n}{\cos \alpha}+L_{0}
\end{array}\right.
$$

Table 1 Torque spring design parameters

\begin{tabular}{lc}
\hline \multicolumn{1}{c}{ Design parameter } & Value \\
\hline Number of effective springs $(n)$ & 8 \\
Mean diameter of coil $(D) / \mathrm{mm}$ & 20 \\
Material diameter $(d) / \mathrm{mm}$ & 3 \\
Spring stiffness $(T) / \mathrm{N} \cdot \mathrm{mm} \cdot \mathrm{deg}^{-1}$ & 28.44 \\
Spring pitch $(t) / \mathrm{mm}$ & 3.5 \\
Free spring height $\left(H_{0}\right) / \mathrm{mm}$ & 31 \\
Helical angle $(\alpha) /\left({ }^{\circ}\right)$ & 3.18 \\
Spring expansion length $\left(L_{s} / \mathrm{mm}\right.$ & 513.2 \\
\hline
\end{tabular}




\subsubsection{Intelligent tillage depth control system}

The intelligent tillage depth control system consists of the intelligent decision system and the pneumatic control system. The angle sensor can monitor the deflection angle of the three articulations in real-time and input the detected value into the intelligent decision system. The intelligent decision system first converts the deflection angle value into the tillage depth deviation $h$ and the change rate $\mathrm{d} h$, and then makes an intelligent decision based on the fuzzy algorithm, formulating the air spring force $F$ adjustment strategy and outputting the air pressure control signal. After receiving the control signal, the air pressure control system regulates the air spring force $F$ by means of an electrical proportional valve. The air storage tank, air compressor, and other mechanisms can guarantee a sufficient air supply. The air pressure gauge and solid state relay monitor the air pressure in the air spring in real-time to ensure the accuracy of the air pressure adjustment.

The fuzzy algorithm for the intelligent tillage depth control system takes the tillage depth deviation $h$ and the rate of change $\mathrm{d} h$ as inputs and the spring thrust $F$ as outputs, and designs a Mamdani-type dual-input-single-output fuzzy controller. As shown in Figure 6, improve the system response and reduce the complexity of fuzzy thrust, the system sets 21 fuzzy control rules as shown in Figure $6 \mathrm{~b}$, using a Gaussian-type function as the input quantity affiliation function and a trigonometric function as the output quantity affiliation function. The fuzzy approximate inference rule (Equation (7)) is derived through the total fuzzy implication relation $R$ synthesis algorithm. During operation, the intelligent tillage depth control system specifies the air spring inference value $F$ according to the fuzzy approximate inference rule, and the relationship between the input and output quantities is shown in Figure 7.

$$
F_{i j}=\left(h_{i} \cdot \mathrm{d} h_{j}\right) \bigcup_{i=1}^{21} R_{i}
$$

where, $F_{i j}$ represents the adjustment force corresponding to the depth change of $i$ and the depth change rate of $j ; h_{i}$ represents the depth change of $i$; $h_{j}$ represents the change rate of $j$.
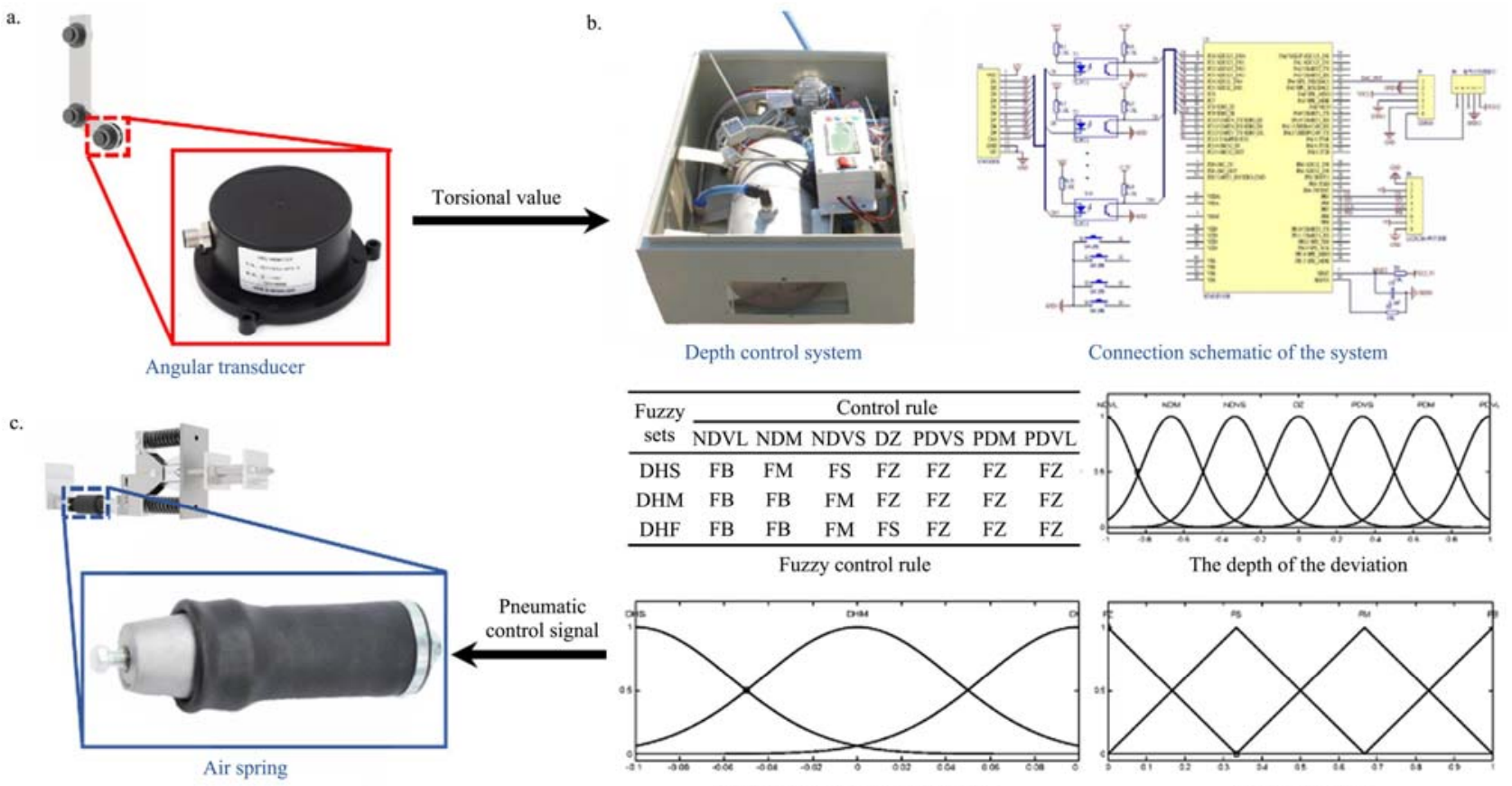

Connection schematic of the system
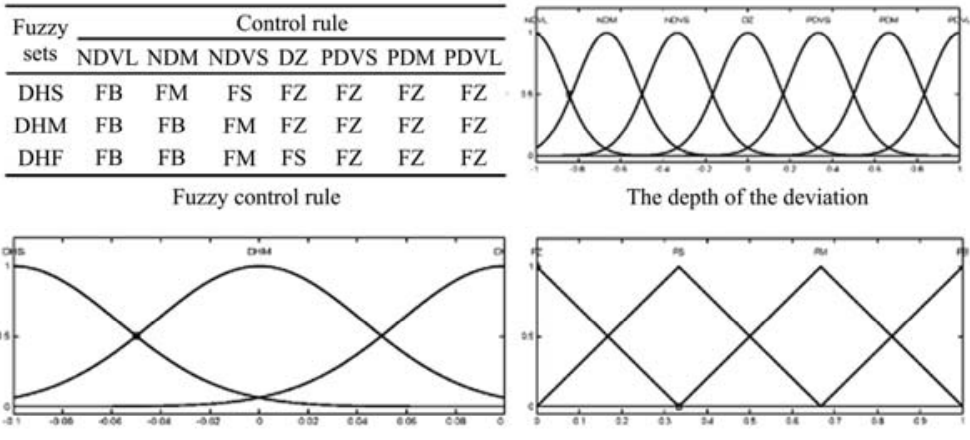

Rate of change of depth deviation

Fuzzy control rule

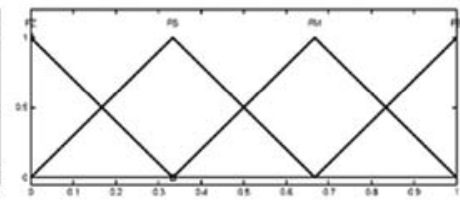

Air spring thrust

Note: Depth deviation settings: large negative deviation (NDVL), moderate negative deviation (NDM), small negative deviation (NDVS), zero deviation (DZ), small positive deviation (PDVS), moderate positive deviation (PDM), large positive deviation (PDVL); Depth deviation variation rate settings: slow (DHS), moderate (DHM) and fast (DHF); Gas spring thrust settings: zero thrust (FZ), small thrust (FS), medium thrust (FM) and large thrust (FB).

Figure 6 Composition of the intelligent decision system and the pneumatic control system of the intelligent tilling depth control system

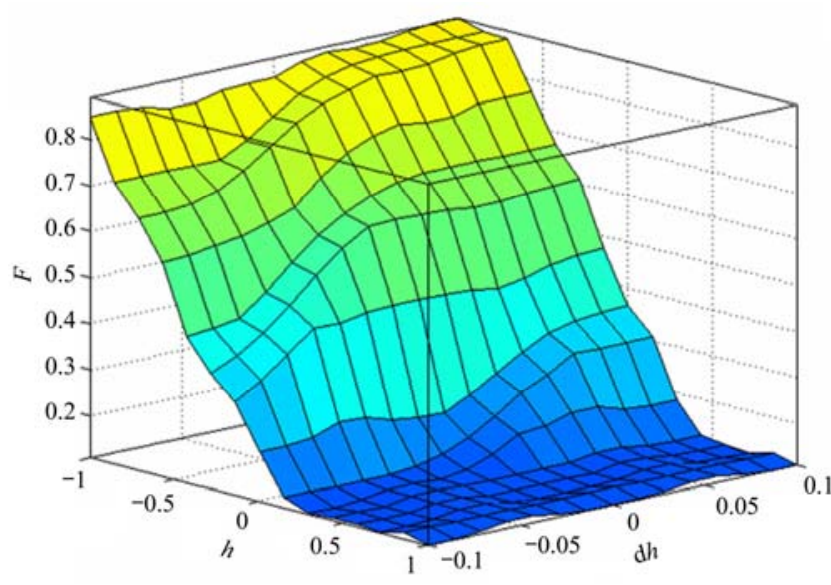

Figure 7 Diagram of the relationship between the input and output quantities of the inferred values of the air spring

\subsection{Integrated design of bionic stubble breaking-deep loosening combined tillage machine}

As shown in Figure 8, the BSD consists of the frame, the bionic stubble-breaking mechanism, the stubble clearance wheel and the bionic self-excited vibrating deep loosening device. The working width of the BSD is $1300 \mathrm{~mm}$ with 3 operating lines of the $\mathrm{BSD}$, and the line spacing is $650 \mathrm{~mm}$, and the total power is 78.29-89.48 kW. During operation, the bionic stubble breaking mechanism breaks down the roots remaining in the soil, and then a deep loosening zone is cleared by the stubble clearance wheel. The bionic self-excited vibration deep loosening device carries out a deep loosening operation in the deep loosening zone.

\section{Materials and experiment methods}

\subsection{Experiment site and instrumentation}

The experiment site is the teaching and research base of Jilin 


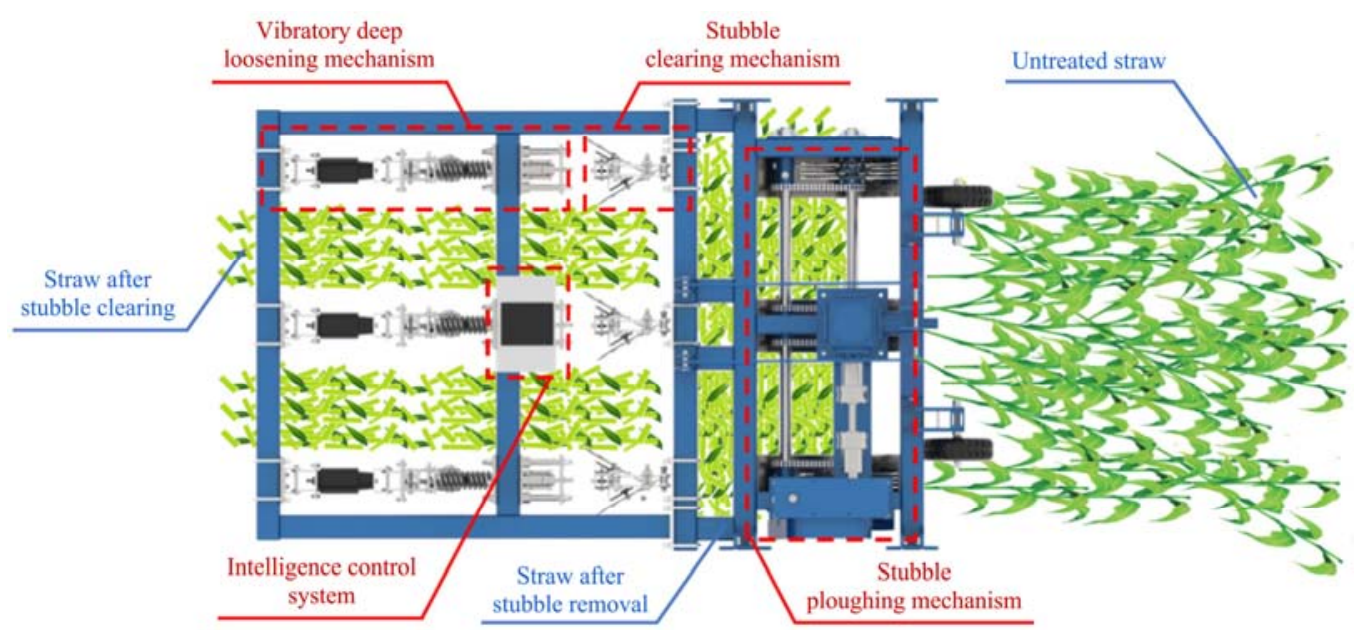

Figure 8 Schematic diagram of the BSD

University in Changchun, Jilin Province, China $\left(43^{\circ} 55^{\prime} \mathrm{N}\right.$, $\left.125^{\circ} 16^{\prime} \mathrm{E}\right)$. The climate of the experiment site is temperate monsoon climate, with high temperature and rain in summer and cold and dry in winter, and the soil type is black clay with a ground slope $<1^{\circ}$. Soil conditions at the experiment site are shown in Table 2. Soil temperature was measured by an 11000 thermometer (Deltatrak Technologies, USA), soil moisture was determined by the MS-350 soil moisture experimenter from Spectrum, USA, soil firmness was determined by the SC-900 soil firmness experimenter from Spectrum, USA and $\mathrm{pH}$ was determined by the HT-PHJ Soil acidity was determined by a soil acidity meter (Qingdao LUBO Company). The varieties planted in test sites was Xianyu 335 and the planting pattern was traditional ridge planting with annual no-till sowing operations in spring, straw return operations, and deep loosening tilling operations in autumn.

Table 2 Soil physical and chemical properties of the teaching and research base of Jilin University

\begin{tabular}{lc}
\multicolumn{1}{c}{ Properties } & Values \\
\hline Soil texture & Clay \\
Soil cone index $/ \mathrm{MPa}$ & 0.977 \\
Soil bulk density $/ \mathrm{g} \cdot \mathrm{cm}^{-3}$ & 1.098 \\
Soil moisture content $/ \%$ & 18.8 \\
Soil temperature $/{ }^{\circ} \mathrm{C}$ & 16.1 \\
Crop planting density $/ \mathrm{plants} \cdot \mathrm{hm}^{-2}$ & $50000-70000$ \\
Plant spacing $/ \mathrm{mm}$ & 220 \\
Line spacing $/ \mathrm{mm}$ & 650 \\
Stubble height $/ \mathrm{mm}$ & $50-100$ \\
\hline
\end{tabular}

\subsection{Experimental design}

The core indexes of the BSD are stubble breaking rate, tilling depth stability, and specific fuel consumption. This study set 1 GZMN-3 power disc harrow-self-excited vibration deep loosening combined machine (DHV) and the 1SZL-3 power stubble-breaking blade-self-excited vibration deep loosening combined machine (SCV) as comparison experiment group (the two types of machines commonly used in the Phaeozem region of northeast China) to study the influence of the BSD on the core indexes under different operating speed conditions.

The experiment took place from October 14 to 20, 2020. Corn harvesting and straw crushing returning to the field were just completed before the experiment, with maize root stubble left in the soil (average depth of root stubble $30 \mathrm{~cm}$ ) and maize straws were covered on the surface $(30 \%$ return, straw length $10.6 \mathrm{~cm}$, mulch thickness $9.6 \mathrm{~cm}$ ). As shown in Figure 9, the experiment plot was divided into three large blocks prior to the experiment and each large block was divided into three plot blocks. Each block is divided into five data collection areas, each with a length of $50 \mathrm{~m}$ and a $10 \mathrm{~m}$ speed adjustment area at each end. The width of each plot block was three monopolies and the length was $350 \mathrm{~m}$. Each large block corresponded to one implement and each plot block corresponded to one implement advance speed. The specific experiment combinations and experiment block divisions are shown in Figure 9.

All three implements were powered by a John Deere 1204 tractor and the operating parameters were set to those most commonly used in the area: $12 \mathrm{~cm}$ for stubble breaking and $40 \mathrm{~cm}$ for deep loosening.

\subsection{Experiment methods for experiment indicators}

\subsubsection{Core indicators}

(1) Stubble breaking rate

Before the whole machine is operated, the number of stubbles on each data collection area is counted and recorded as a total $n_{i}$. After the machine has finished working, the number of stubbles that have been completely broken is counted and recorded as a total $n_{i 1}$; the average of the five data collection areas is calculated as the average stubble breaking rate for the area according to Equation (8).

$$
y=\frac{\sum_{i=1}^{5} \frac{n_{i}}{n_{i 1}}}{5} \times 100 \%
$$

where, $n_{i}$ represents the number of all stubble on each data collection area; $n_{i 1}$ represents the number of completely broken stubble.

(2) Coefficient of variation of tillage depth

After the work with the implements is completed, the tractor pulls the suspended implements for $50 \mathrm{~m}$. A point is selected every $2 \mathrm{~m}$ or so along the direction of the tractor, and the distance from the surface of the unploughed land to the bottom of the furrow is measured using a tilling depth ruler after the bottom of the furrow has been cleaned manually, and the coefficient of variation of the tilling depth in the area is calculated according to Equation (9).

$$
\begin{aligned}
& S=\sqrt{\frac{\sum\left(x_{i}-x\right)^{2}}{n-1}} \\
& C V=\frac{S}{x} \times 100 \%
\end{aligned}
$$

where, $S$ is the standard deviation of the actual tillage depth 
measurement, $\mathrm{mm} ; x$ is the average tillage depth of each measurement point of the actual tillage depth, $\mathrm{mm} ; \mathrm{CV}$ is the coefficient of variation of the tillage depth uniformity evaluation index, $\%, x_{i}$ is the actual tillage depth value of the measurement point, mm. $n$ is the number of measurement points, the actual number of measurement points, $n$ is taken as 25 .

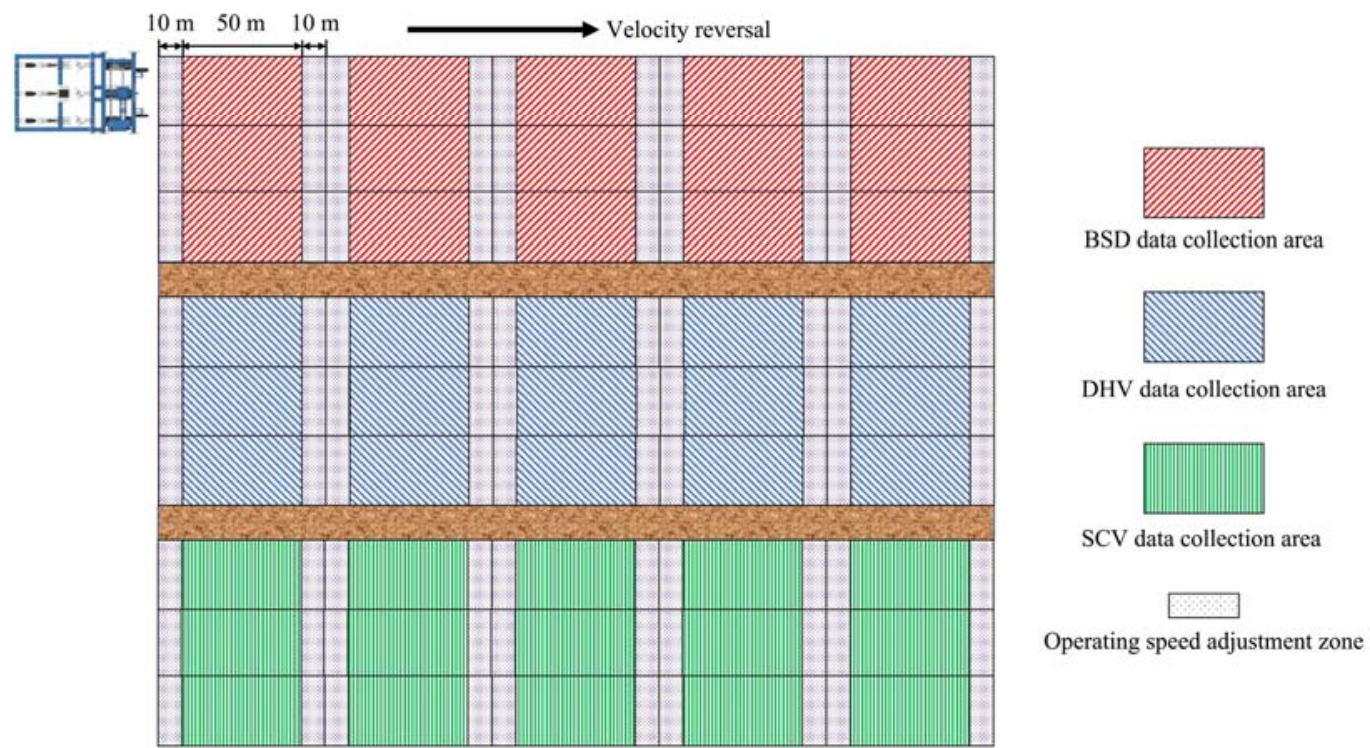

Note: BSD represents the bionic stubble-deep loosening combined tillage machine; DHV represents the disc harrow-self-excited vibration deep loosening combined machine; SCV represents the stubble-breaking blade-self-excited vibration deep loosening combined machine, the same as below.

Figure 9 Map showing the division of the experiment area

(3) Specific fuel consumption

The tractor's fuel gauge count is recorded before and after each operation, and the specific fuel consumption of the tractor in this block can be derived from Equation (10).

$$
G E=\frac{1}{5} \sum_{i=1}^{5} \frac{1000\left(x_{i}-x_{i}^{\prime}\right) v}{p s}
$$

where, $G E$ represents specific fuel consumption; $x_{i}$ represents the fuel meter value at the beginning; $x_{i}^{\prime}$ represents the fuel meter value at the end; $v$ represents the operating speed, $\mathrm{m} / \mathrm{s} ; s$ represents the operating distance, $\mathrm{m} ; p$ represents the operating power, $\mathrm{kW}$.

\subsubsection{Supporting indicators}

(1) Resistance torque for stubble breaking operations

Torque sensors (ZJ-AP) were installed at the stubble-breaking blade shafts of the three implements to measure the resistance torque of the implements' stubble-breaking devices in real-time. The data for each implement was recorded in five data acquisition zones using a PCI-9223 data acquisition card (ADLINK Technology Ltd.) to produce a time t-average resistance torque scatter plot and average torque values for the entire operation.

(2) Self-excited vibratory deep loosening shovel deflection angle

Angle sensors are installed at the hinge of all three implements of the vibrating deep loosening device, with the SCV and DHV having only one hinge mechanism and the BSD having three hinges. The deflection angle of each articulating mechanism is measured in real-time and the data for each articulating mechanism within the five data acquisition zones is recorded via the PCI-9223 data acquisition card (ADLINK Technology Co., Ltd.) to produce a time t-average deflection angle $\alpha$ scatter plot and the average deflection angle value for the entire operation.

(3) Traction resistance of the machine

The tension sensors were separately installed at the joints between the three implements and the tractor to measure the total traction force in real-time. The data for each implement within the five-segment data acquisition zone was recorded via a PCI-9223 data acquisition card (ADLINK Technology Ltd.) to produce a time $t$-average traction resistance scatter plot, as well as the average traction resistance throughout the operation.

\subsection{Statistical data processing methods}

The data were statistically processed and correlated using Excel and SPSS software and plotted using Origin software. ANOVA and LSD were used to experiment whether there was a significant effect of the different machines on the experiment indicators.

\section{Results and discussion}

\subsection{Stubble breaking rate}

From Figure 10a, LSD's analysis showed that the stubble breaking rate of the bionic stubble breaking-deep loosening combined tillage machine (BSD) was significantly higher than that of the other two machines at the same operating speed $(p<0.05)$. The stubble breaking rate of the BSD was maintained at $95 \%$, which was $9.62 \%$ and $10.67 \%$ higher than that of the DHV and the SCV. From Figures 10b-10d, the LSD's analysis showed that the stubble breaking resistance torque of the BSD was significantly lower than that of the other two machines at the same operating speed $(p<0.05)$. The stubble breaking resistance torque of the BSD was kept at $64 \mathrm{~N} \cdot \mathrm{m}$, which was $31.25 \%$ and $33.33 \%$ lower than that of the DHV and SCV operation machine, respectively. As the operating speed increases, the cutting resistance torque of all three implements increases significantly and the stubble breaking rate decreases significantly, with the BSD decreasing the least.

The prerequisite for the maize rootstock to be shredded is that the maximum drive available to the stubble-breaking blade is greater than the stubble resistance. As shown in Figure 11, the maize rootstock consists mainly of the epidermis and the pith. The maize epidermis is composed of fibres and the pith is composed of lignin and spongy bodies. Before the maize rootstock epidermis is cut, all fibres are in a stretched state and the pith is in a compressed state, and the operational resistance can be derived from Equation (11). As the stubble-breaking blade rotates, the tensile strain $\gamma_{k}$ of the fiber gradually increases. When the tensile strain exceeds the ultimate tensile strain $\gamma_{k}^{\prime}$ of the maize 
fiber, the epidermis will be completely cut off, meanwhile, the operating resistance $F_{t}$ reaches the maximum. According to Equation (11), the larger the contact area between the stubble-breaking blade and the root and stem is, the greater the maximum resistance $F_{\max }$ of cutting maize epidermis is. As shown in Figure 11d, the BSD uses symmetrical cutting without bending of the maize rootstock, while the bionic segmental serrated structure minimizes the contact area. In summary, the BSD is the easiest to pierce the skin of the maize rootstalk, with the lowest stubble resistance and the highest stubble breaking rate for the same tractor power output.

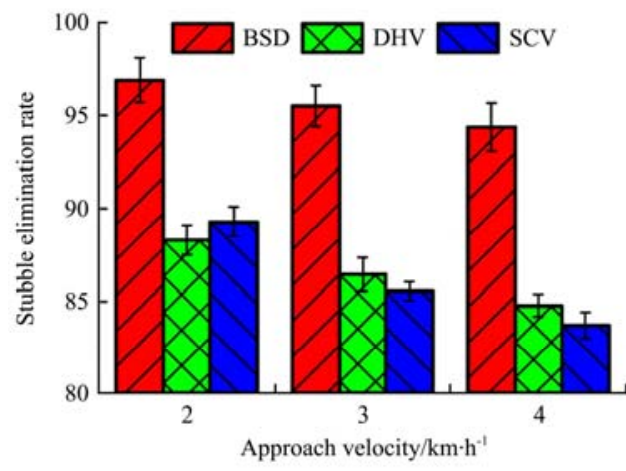

a. Stubble breaking rate

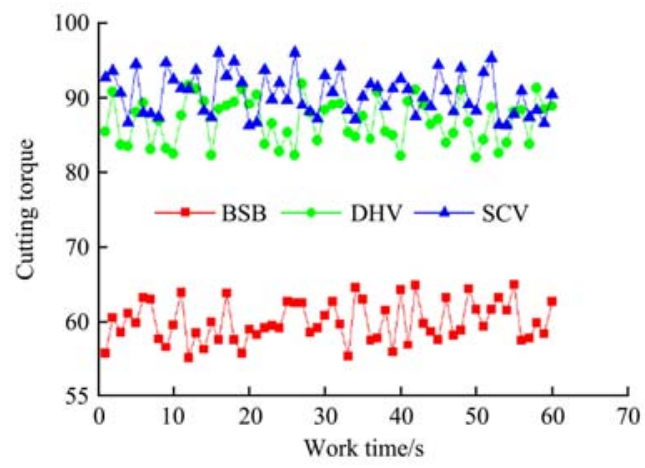

c. Operating speed of $3 \mathrm{~km} / \mathrm{h}$

$$
\begin{aligned}
& F_{t}=\int_{0}^{S} E \varepsilon d s+\sum_{K=1}^{m} G \gamma_{\mathrm{k}} \sin \left(\frac{\theta}{2}\right) \\
& \text { when } \gamma_{\mathrm{k}}=\gamma_{\mathrm{k}}{ }^{\prime} \Rightarrow F_{t}=F_{\max }
\end{aligned}
$$

where, $E$ represents the elastic modulus of pith, $\mathrm{Pa} ; \varepsilon$ represents the other shrinkage of pith, $\% ; G$ represents the straw epidermis tensile pith, $\mathrm{N} ; s$ represents the medullary cross-sectional area, $\mathrm{mm}^{2} ; \gamma_{k}$ represents the tensile shape variable, $\mathrm{mm}$; $\theta$ represents the blade edge angle, $\left({ }^{\circ}\right)$; and $\gamma^{\prime}{ }_{k}$ represents the maximum tensile shape variable, $\mathrm{mm} ; F_{t}$ represents the cutting resistance at time $t, \mathrm{~N}$, and $F_{\max }$ represents the maximum cutting resistance, N.

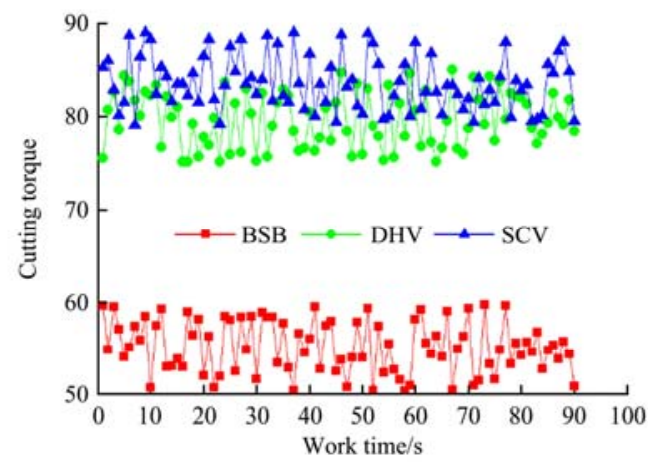

b. Operating speed of $2 \mathrm{~km} / \mathrm{h}$

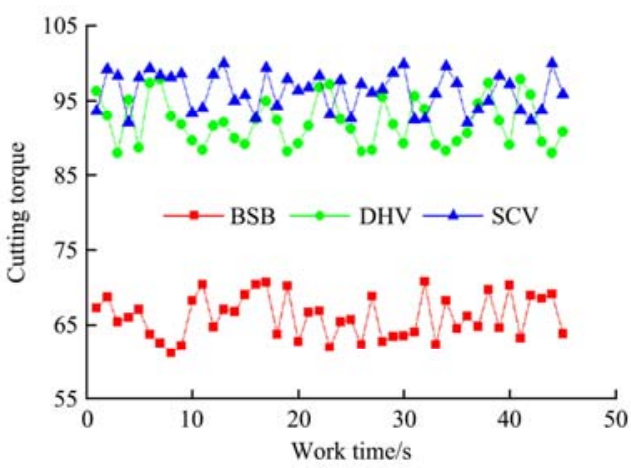

d. Operating speed of $4 \mathrm{~km} / \mathrm{h}$

Figure 10 Stubble breaking rate and cutting torque of the three medium machines at different operating speeds
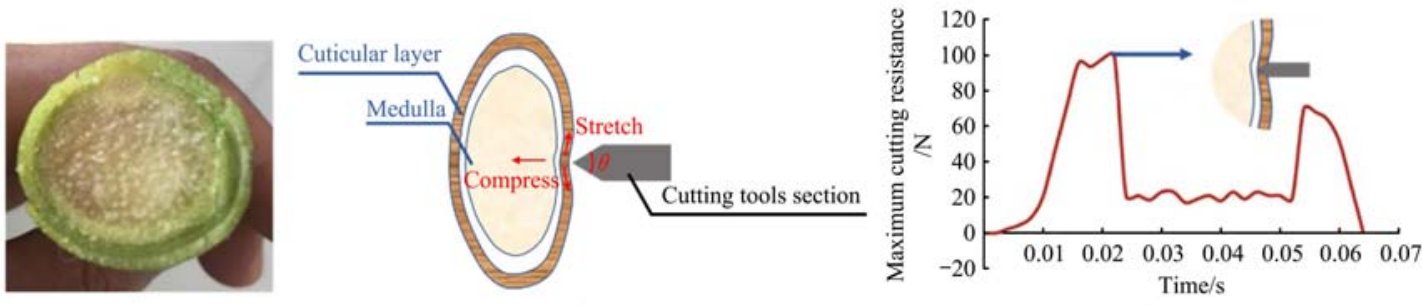

a.

b. c.

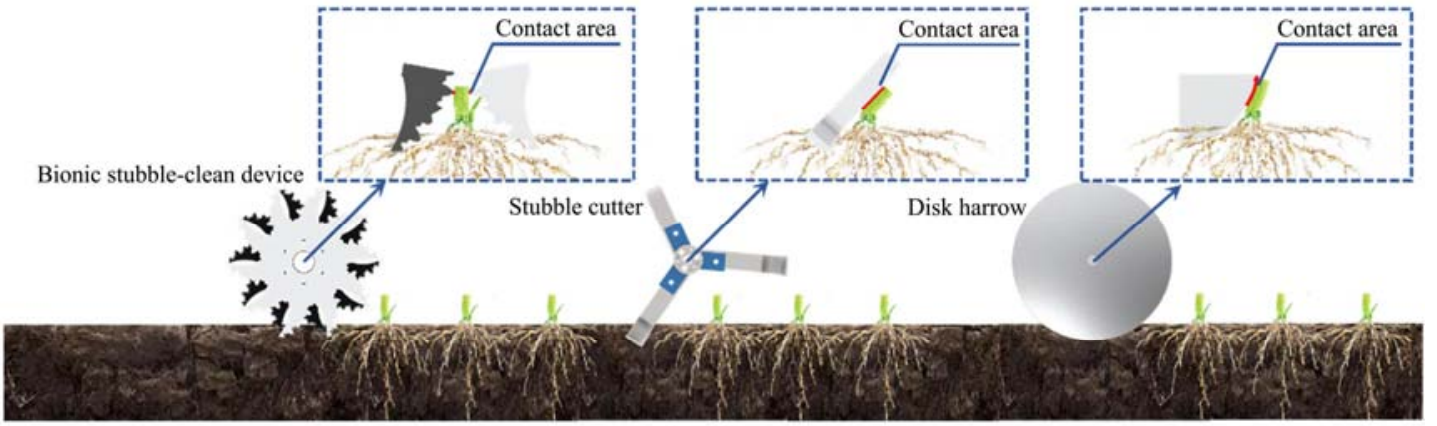

d.

Figure 11 Schematic diagram of three types of machine for stubble principle

\subsection{Tillage depth stability}

As can be seen from Figure 12a, LSD's analysis showed that the coefficient of variation of tillage depth was significantly lower $(p<0.05)$ for the BSD than for the other two implements at the same operating speed. The coefficient of variation of tilling depth is 9.51, which is $9.99 \%$ and $9.67 \%$ lower than that of the DHV and 
the SCV respectively. From Figures 12b-12d, LSD's analysis showed that at the same operating speed, there was no significant difference among the deflection angle of the DHV's shovel, the SCV's shovel and the average of three deflection angles of the BSD $(p<0.05)$. But the three deflection angles of the BSD showed less variation. As the operating speed increases, the deflection angle and the variation coefficient of the tillage depth of all three implements increase significantly, with the smallest increase in the coefficient of variation of the tillage depth of the BSD.

When the combined tillage machine is operating, the self-excited vibratory deep loosening shovel deflects due to real-time changes in soil resistance, resulting in a change in tillage depth. The value of the variation in tillage depth depends on the deflection radius $L$, the deflection angle $\alpha$ and the deep loosening shovel construction angle $\beta$. The deflection angle $\alpha$ depends on the modulus of elasticity $K$ of the deep loosening mechanism. It can be seen in Equation (5) that when the same parameters are

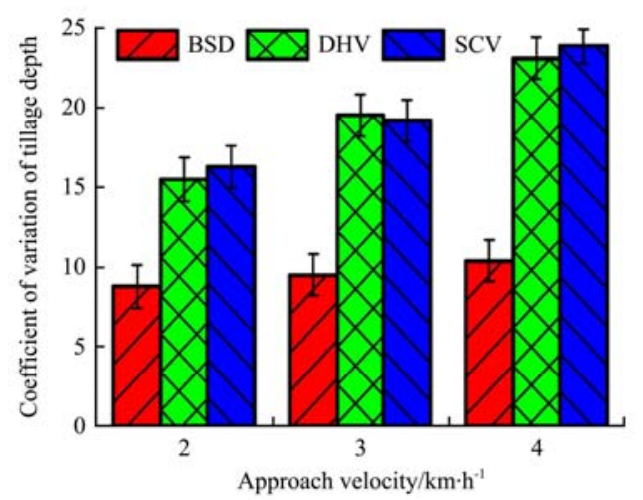

a. Coefficient of variation of tillage depth

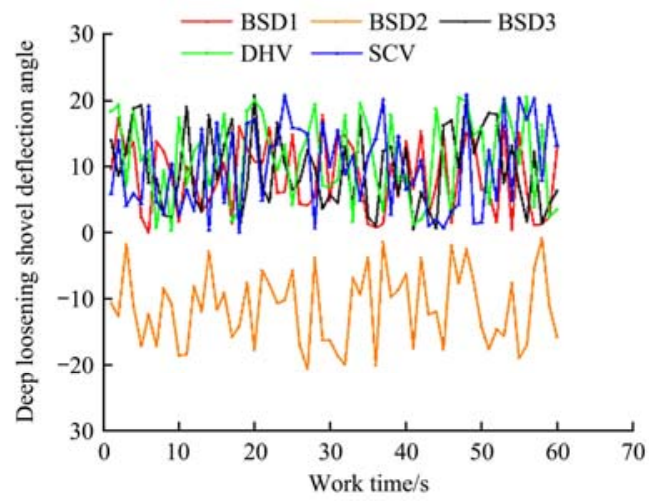

c. Operating speed of $3 \mathrm{~km} / \mathrm{h}$ selected for the three torsion springs of the bionic elastic system, the modulus of elasticity of the vibratory deep loosening mechanism of the three implements is equal, so there is no significant difference in the overall deflection angle of the deep loosening shovel of the three implements. Figure 13 shows that when the bionic deep loosening shovel is unbalanced in operation, the articulation (1) and (3) can drive the deep loosening shovel to deflect in the same direction, while the articulation (2) will produce the opposite torque, which is equivalent to reducing the equivalent deflection radius $L^{\prime}$ of the deep loosening shovel (1) and (2) and (3) in the text corresponds to the criteria in Figure 5). Therefore, it can be seen in Equation (12) that under the condition of the same depth and length of deep loosening shovel, the bionic elastic system can reduce the amplitude caused by the self-excited vibration of the deep loosening shovel, and then play a role in regulating the tilling depth. As a result, the BSD has the smallest variation in tillage depth.

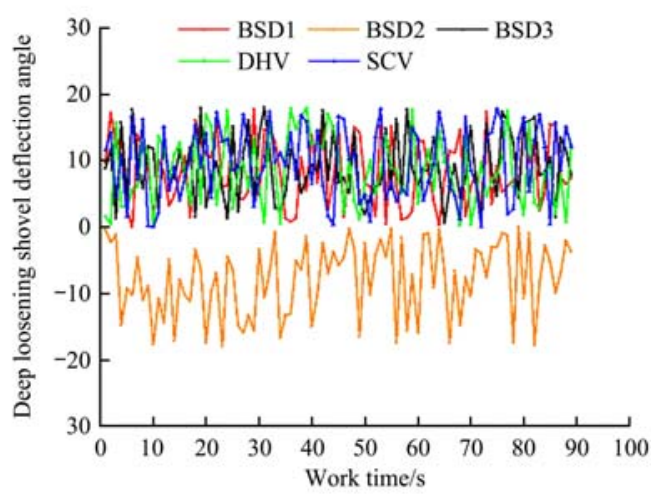

b. Operating speed of $2 \mathrm{~km} / \mathrm{h}$

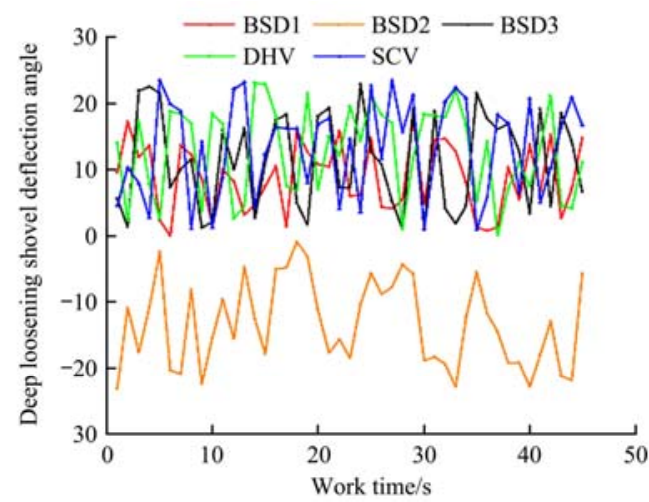

d. Operating speed of $4 \mathrm{~km} / \mathrm{h}$

Figure 12 Coefficient of variation of tillage depth and deflection angle of the deep loosening shovel for the three implements at different operating speeds

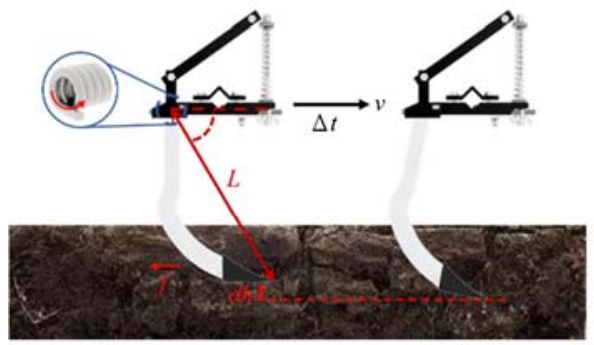

a.

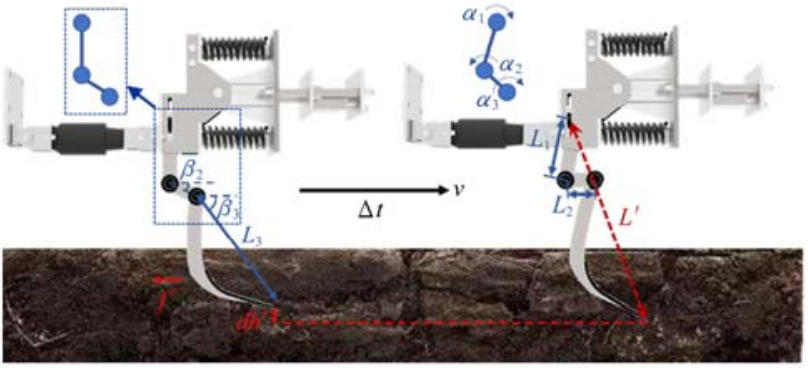

b.

Note: $L_{1}, L_{2}$ and $L_{3}$ represent the rotation radius of $1,2,3$ connecting rod; $f$ and $f^{\prime}$ represent the soil resistance; $d h$ and $d h^{\prime}$ represent the variation of tillage depth; $L$ represents the rotation radius of traditional deep loosening shovel; $L^{\prime}$ represents the equivalent rotation radius; $\beta_{1}, \beta_{2}$ and $\beta_{3}$ respectively represent the included angle between the equivalent radius of the initial position of connecting rod 1, 2, 3 and the horizontal plane.

Figure 13 Variation in deflection of the hinge joint of a deep loosening shovel 


$$
\left[\begin{array}{l}
V h=L[\sin (\beta+\alpha)-\sin \beta] \\
V h^{\prime}=L^{\prime}\left[\sin \left(\beta+\alpha^{\prime}\right)-\sin \beta\right]=L_{3}\left[\sin \left(\beta_{3}+\alpha_{3}\right)-\sin \beta_{3}\right]- \\
\quad L_{2}\left[\sin \beta_{2}-\sin \left(\beta_{2}-\alpha_{2}\right)\right]-L_{1}\left(1-\cos \alpha_{1}\right) \\
L \sin \beta=L_{1}+L_{2} \sin \beta_{2}+L_{3} \sin \beta_{3} \\
L \cos \beta=L_{2} \cos \beta_{2}+L_{3} \cos \beta_{3}
\end{array}\right] \Rightarrow \Delta h>\Delta h^{\prime}
$$

\subsection{Combined operation specific fuel consumption}

The analysis of BSD in Figure 14a showed that BSD can reduce specific fuel consumption by $36 \mathrm{~g} / \mathrm{km} \cdot \mathrm{h}$ and $40 \mathrm{~g} / \mathrm{km} \cdot \mathrm{h}$,

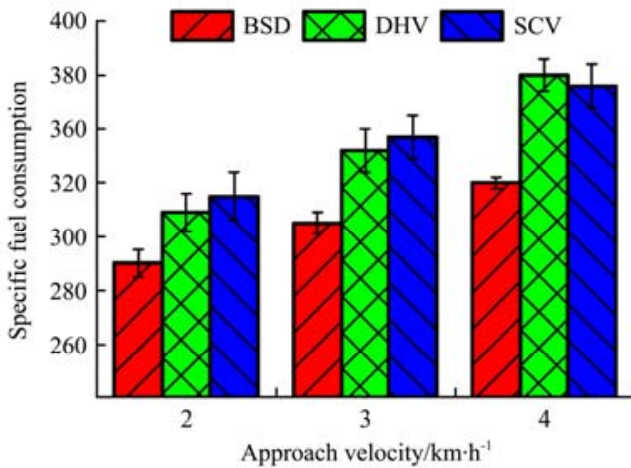

a. Specific fuel consumption

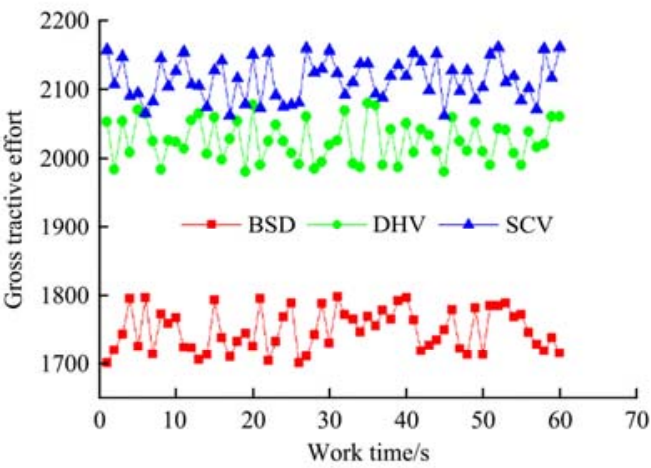

c. Operating speed of $3 \mathrm{~km} / \mathrm{h}$ respectively, compared to the DHV and the SCV. As can be seen from Figures 14b-14d, LSD's analysis showed that the total tractive effort of the BSD was significantly lower than the other two implements $(p<0.05)$. The total traction force of the BSD was maintained at $2644 \mathrm{~N}$, which could be reduced by $10.79 \%$ and $14.59 \%$ compared to the DHV and SCV respectively. As the operating speed increases, the total tractive effort and specific fuel consumption of all three implements increase significantly. However, BSD had the smallest increase in specific fuel consumption.

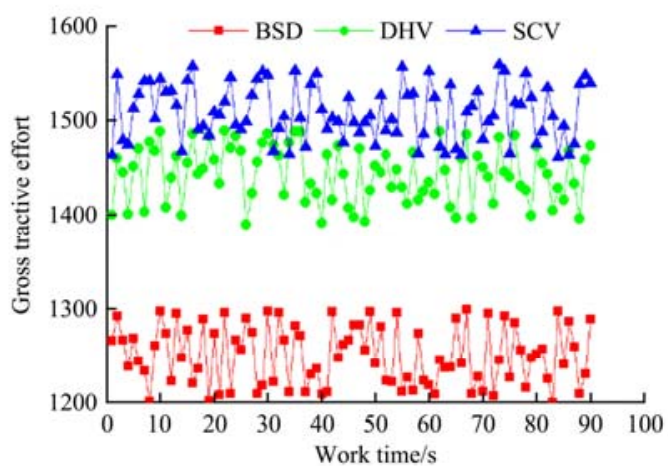

b. Operating speed of $2 \mathrm{~km} / \mathrm{h}$

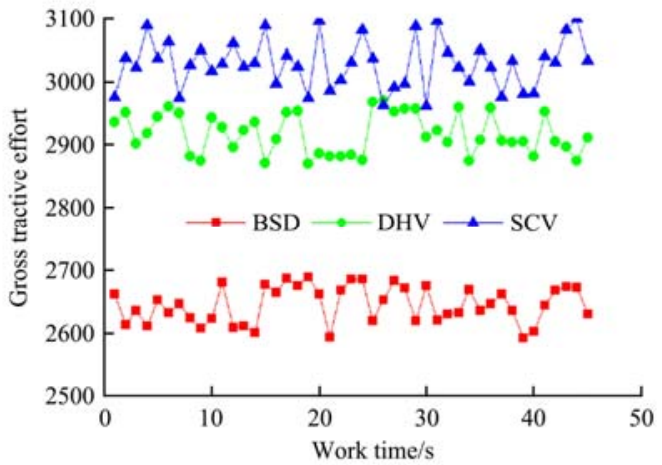

d. Operating speed of $4 \mathrm{~km} / \mathrm{h}$

Figure 14 Graph of the change in specific fuel consumption and total tractive effort for the three implements at different operating speeds

The energy consumption during the operation is mainly composed of the forward movement energy consumption $Q_{1}$, stubble breaking power consumption $Q_{2}$ and reciprocating deflection energy consumption $Q_{3}$ of deep loosening shovel, while the elastic potential energy stored in the elastic mechanism $Q_{4}$ can offset some of the energy consumption. Therefore, the operating energy consumption can be derived from Equation (13).

$$
\left[\begin{array}{l}
Q=Q_{1}+Q_{2}+Q_{3}-Q_{4} \\
Q^{\prime}=Q_{1}+Q_{2}+Q_{3}-Q_{4}^{\prime}
\end{array}\right]\left\{\begin{array}{l}
Q_{1}=\int_{0}^{\frac{s}{v}} F_{t} v \mathrm{~d} t \\
Q_{2}=\int_{0}^{\frac{s}{v}} N_{t} \omega \mathrm{d} t+\Delta L \cdot \int_{0}^{h}(c+\sigma \tan \varphi) a \mathrm{~d} h \\
Q_{3}=\int_{0}^{h} \int_{0}^{\Delta \bar{L}}(c+\sigma \tan \varphi) a \mathrm{~d} h \mathrm{~d} L \\
Q_{4}^{\prime}=\int_{0}^{\frac{s}{v}}\left(k_{1} \alpha_{1 t}{ }^{2}+k_{2} \alpha_{2 t}{ }^{2}+k_{3} \alpha_{3 t}{ }^{2}\right) \mathrm{d} t \\
Q_{4}=\int_{0}^{\frac{s}{v}} k \alpha_{t}^{2} \mathrm{~d} t
\end{array}\right.
$$

When all three implements are operating at the same forward speed $v$, the forward movement energy consumption $Q_{1}$ is proportional to the traction force. The total traction of the implements is influenced by the rate of stubble breaking, stubble resistance, and soil resistance. The higher the stubble breaking rate is, the better trafficability of the implement and the lower the traction resistance is. The greater the stubble resistance and soil resistance, the greater the overall traction resistance of the implement. When operating in the same soil conditions, the BSD has the highest stubble breaking rate and the lowest stubble resistance, so its $Q_{1}$ value is the lowest.

During the stubble breaking operation, the rootstock is affected by the driving force of the blade, the supporting force of the soil, and the friction force. As shown in Figure 15, when the horizontal component of the blade drive force is greater than the adhesion force between the soil and the rootstock, the rootstock will slip. Therefore, the stubble-breaking power consumption $Q_{2}$ is mainly composed of the power consumption in the rotating of the stubble-breaking blade and the power consumption of the rootstock displacement. The three stubble breaking mechanisms were connected to the same type of power unit during the experiment, so the difference in power consumption among them is due to the rootstock sliding distance $\Delta L$. The symmetrical rotation of the bionic stubble mechanism allows the rootstock to be equilibrium at all times and the slip distance is much less than that of a conventional stubble mechanism, so its $Q_{2}$ value is minimal.

It can be seen in the conclusions of the previous analysis that the articulation of the bionic deep loosening unit (2) limits the vibration amplitude of the deep loosening shovel, which is equivalent to reducing the overall deflection radius $L^{\prime}$ of the deep loosening shovel. 
Equation (14) shows that reciprocating deflection distance $\Delta \mathcal{L}$ of BSD is minimal. Equation (13) shows that the $Q_{3}$ value of the BSD is the lowest.

$$
\Delta \widehat{L}=\frac{\alpha \pi L}{180}
$$

The elastic system of the BSD is designed in series-parallel so that the equivalent elastic modulus of the elastic system remains constant, and the same deflection angle as the other two machines can be obtained at hinge (1), while a certain deflection angle will be produced at hinges (2) and (3) (1) and (2) and (3) in the text corresponds to the criteria in Figure 5). Therefore, combined with Equation (12), it can be seen that the BSD has the strongest elastic potential energy storage capacity, and its $Q_{4}$ value is the largest.
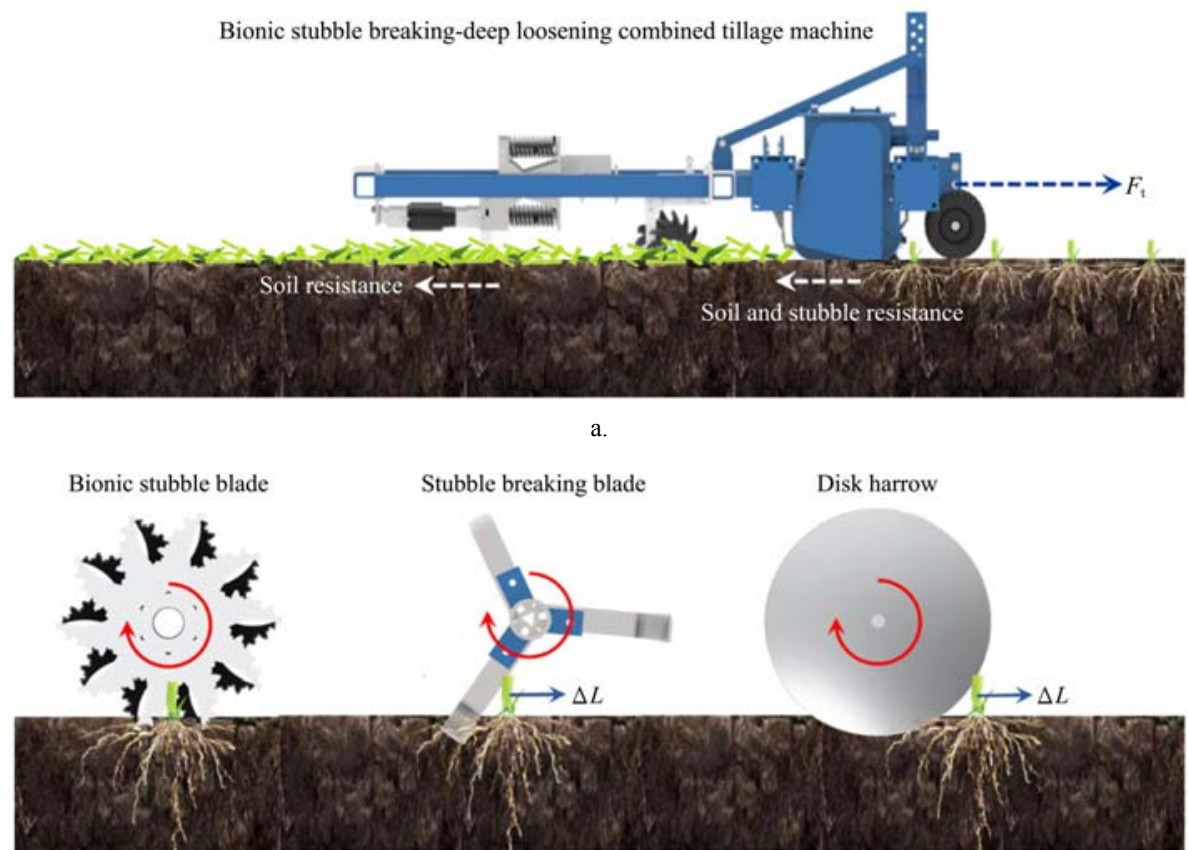

Deep-shovel by self-excited vibration

Bionic deep-shovel by self-excited vibration

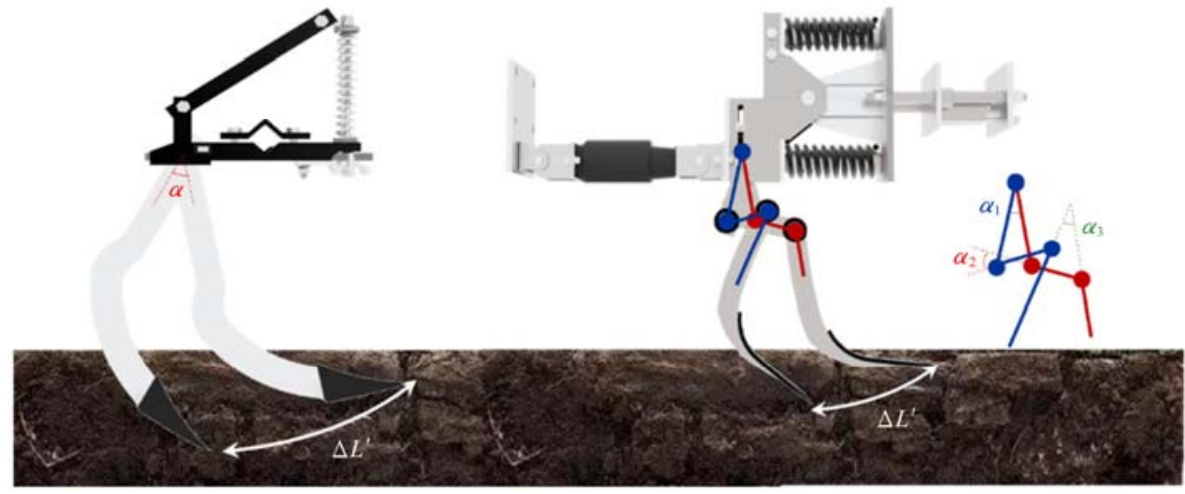

c.

Note: $\Delta L$ represents the root stubble offset in the breaking operation, and $\Delta L^{\prime}$ represents the maximum tillage depth offset in the tillage depth operation.

Figure 15 Equipment energy consumption diagram

\section{Conclusions}

A bionic stubble removal device was designed, which included a segmented serrated blade structure and a symmetrical rotary drive system. It reproduces the bite pattern of the locust's mouthparts to corn rootstock efficiently. Higher stubble rates can be achieved with the same output torque. The experiment results show that the bionic stubble breaking device can improve the stubble breaking rate by $9.62 \%$ and $10.67 \%$ and reduce the stubble breaking torque by 28 $\mathrm{N} \cdot \mathrm{m}$ and $33 \mathrm{~N} \cdot \mathrm{m}$, respectively, compared to the traditional power disc harrow and chopper blade.

A series-parallel composite bionic elastic system and an intelligent tilling depth control system were designed to enable the bionic self-excited vibratory deep loosening device to restore the unique biological structure of the hare's claw, toe, and nail.
Therefore, under the same conditions, the bionic elastic system has a smaller variation in tillage depth. The experiment results showed that the bionic self-excited vibratory deep loosening device can reduce the coefficient of variation of tillage depth by $12.73 \%$ and $13.48 \%$ compared to the traditional single-articulated vibratory deep loosening shovel.

The BSD designed in this paper has a higher stubble breaking rate and lower stubble breaking resistance, which can improve the overall trafficability of the machine and obtain lower traction resistance. The experiment results showed that compared to the DHV and the SCV, the BSD can reduce the specific fuel consumption by $36 \mathrm{~g} / \mathrm{km} \cdot \mathrm{h}$ and $40 \mathrm{~g} / \mathrm{km} \cdot \mathrm{h}$. The operational performance of all three machines decreases with the increase in operating speed, but the BSD has the lowest decrease, which indicates that the BSD is more suitable for high-speed operation. 


\section{Acknowledgements}

The authors acknowledge that the research was financially supported by the National Key Research and Development Project of China (Grant No. 2017YFD0700701), the Natural Science Foundation of China (Grant No. 52075215), and the Science and Technology Development Plan Project of Jilin Province (Grant No. 20190301023NY, 20190701055GH and 20200404008YY), and China Postdoctoral Science Foundation (Grant No. 2020M67085).

\section{[References]}

[1] Gao W S. Development trends and basic principles of conservation tillage. Scientia Agricultura Sinica, 2007; 40(12): 2702-2708.

[2] Liang $\mathrm{Z}, \mathrm{Wu} \mathrm{W}$, Wei $\mathrm{Y}, \mathrm{Hu} \mathrm{K}$. Effects of straw return and regional factors on spatio-temporal variability of soil organic matter in a high-yielding area of northern China. Soil \& Tillage Research, 2015; 145: $78-86$.

[3] Zhao S C, Li K J, Zhou W, Qiu S J, Huang S W, He P. Changes in soil microbial community, enzyme activities and organic matter fractions under long-term straw return in north-central China. Agriculture, Ecosystems and Environment, 2016; 216: 82-88.

[4] Horning L B, Strtler L D, Saxton K E. Surface residue and soil toughness for wind erosion protection. Transactions of the ASAE, 1998; 41(4): 1061-1065.

[5] Dong H F, Li H, Li A J, Yan X G, Zhao C M. Relations between delayed sowing date and growth effective accumulated temperature of maize. Maize Science, 2012; 20(5): 97-101.

[6] Issaka F, Zhang Z, Zhao Z Q, Asenso E, Li J H, Li Y T. Sustainable conservation tillage improves soil nutrients and reduces nitrogen and phosphorous losses in maize farmland in Southern China. Sustainability, 2019; 11(8): 2397 . doi: 10.3390/su11082397.

[7] Qiu H G, Zhang S H, Yang J, Jing Y. Development of China's maize industry challenges in the future and policy suggestions. Journal of Agricultural Science and Technology, 2013; 1: 20-24.

[8] Karayel D. Performance of a modified precision vacuum seeder for no-till sowing of maize and soybean. Soil \& Tillage Research, 2009; 104(1): 121-125.

[9] Zhang B Y, Chen T L, Wang B. Effects of long-term uses of chemical fertilizers on soil quality. Chinese Agricultural Science Bulletin, 2010; 26(11): 182-187.

[10] Magiera T, Zawadzki J. Using of high-resolution topsoil magnetic screening for assessment of dust deposition: comparison of forest and arable soil datasets. Environmental Monitoring and Assessment, 2007; 125(1-3): 19-28.

[11] Lobell D B, Asner G P. Climate and management contributions to recent trends in US agricultural yields. Science, 2003; 299(5609): 1032-1032

[12] He J, Li H W, Chen H T, Lu C Y, Wang Q J. Research progress of conservation tillage technology and machine. Transactions of the CSAM, 2018; 49(4): 1-19. (in Chinese)

[13] Li J W, Jiang X H, Ma Y H, Tong J, Hu B. Bionic design of a potato digging shovel with drag reduction based on the discrete element method (DEM) in clay soil. Appl. Sci., 2020; 10(20): 7096. doi: 10.3390/ app10207096.

[14] Shi L R, Sun W, Wang D, Zhao W Y, Liu Q W, Zhang H, et al. Design and simulation research on the potato bionic digging shovel. Agric. Res. Arid Areas, 2014; 32: 268-272. (in Chinese)

[15] Shahgolia G, Fielkeb J, Saundersb C, Desbiollesb J. Simulation of the dynamic behavior of a tractor-oscillating subsoiler system. Biosyst. Eng. 2010; 106: 147-155.

[16] Ren L Q, Tong J, Li J Q. Soil adhesion and biomimetics of soil-engaging components: a review. J. Agric. Eng. Res., 2001; 79: 239-263.

[17] Fountaine E R. Investigations into the mechanism of soil adhesion. Eur. J. Soil Sci., 1954; 5: 251-263.
[18] Yang X D, Ren L Q. Types and mechanisms of shape drag reduction. Transactions of the CSAM, 2003; 34(1): 130-132. (in Chinese)

[19] Dou Z L, Wang J, Chen D. Bionic research on fish scales for drag reduction. Journal of Bionic Engineering, 2012; 9(4): 457-464.

[20] Han Z W, Mu Z Z, Yin W, Li W, Niu S C, Zhang J Q, et al. Biomimetic multifunctional surfaces inspired from animals. Advances in Colloid and Interface Science, 2016; 234: 27-50.

[21] Qaisrani A R, Chen B C, Ren L Q. Modified and unsmoothed plow surfaces: A means to reduce plowing resistance. Agricultural Engineering of Journal, 1992; 1(3): 115-124.

[22] Tong J, Ren L Q, Chen B C. Geometrical morphology, chemical constitution and wettability of body surfaces of soil animals. International Agricultural Engineering Journal, 1994; 3(1): 59-68.

[23] Zhao J L, Guo M Z, Lu Y, Huang D Y, Zhuang J. Design of bionic locust mouthparts stubble cutting device. Int J Agric \& Biol Eng, 2020; 13(1): 20-28.

[24] Lin Y M, Feng Z M, Wu W X, Yang Y Z, Zhou Y, Xu C C. Potential impacts of climate change and adaptation on maize in northeast China. Agronomy Journal, 2017; 109(4): 1476-1490.

[25] Wegner B R, Osborne S L, Lehman R M, Kumar S. Seven-year impact of cover crops on soil health when corn residue is removed. BioEnergy Research, 2018; 11(2): 239-248.

[26] Liu T H, Liang Z H, Guo J D. Experimental comparison of litchi fruit stalk cutting force. Applied Engineering in Agriculture, 2012; 28(2): 297-302.

[27] Ren L Q, Liang Y H. Biological couplings: Classification and characteristic rules. Science in China Series E: Technological Sciences, 2009; 52(10): 2791-2800.

[28] Maughan J D, Mathanker S K, Fehrenbacher B M, Hansen A C. Impact of cutting speed and blade configuration on energy requirement for Miscanthus harvesting. Applied Engineering in Agriculture, 2014; 30(2): 137-142.

[29] Ma Y H, Wu S Y, Zhuang J, Tong J, Xiao Y, Qi H Y. The evaluation of physio-mechanical and tribological characterization of friction composites reinforced by waste corn stalk. Materials, 2018; 11(6): 901. doi: 10.3390/ ma11060901.

[30] Kang M S, Din A K, Zhang Y, Magari R. Combining ability for rind puncture resistance in maize. Crop Science, 1999; 39(2): 368-371.

[31] Thompson B C, Murray E, Wallace G G. Graphite oxide to graphene. Biomaterials to bionics. Advanced Materials, 2015; 27: 7563-7582.

[32] Zeng Z, Chen Y, Zhang X. Modelling the interaction of a deep tillage too with heterogeneous soil. Comput. Electron. Agric., 2017; 143: 130-138.

[33] Ucgul M, Saunders C, Fielke J M. Discrete element modelling of top soil burial using a full scale mouldboard plough under field conditions. Biosyst. Eng., 2017; 160: 140-153.

[34] Sun J Y, Wang Y M, Ma Y H, Tong J, Zhang Z J. DEM simulation of bionic subsoilers (tillage depth $>40 \mathrm{~cm}$ ) with drag reduction and lower soil disturbance characteristics. Adv. Eng. Softw., 2018; 119: 30-37.

[35] Ucgul M, Fielke J M, Saunders C. Defining the effect of sweep tillage tool cutting edge geometry on tillage forces using $3 \mathrm{D}$ discrete element modeling. Inf. Process Agric., 2015; 2: 130-141.

[36] Du J M, Chen L A, Mak C-W. Energy consumption characteristics of reciprocating motion mechanism and energy saving control method after adding air spring. Machine Tools and Hydraulics, 2016; 44(7): 53-57.

[37] Wang X L, Hu H, Wang Q J, Li H W, He J, Chen W Z. Calibration method of soil contact characteristic parameters based on DEM theory. Transactions of the CSAM, 2017; 48(12): 78-85. (in Chinese)

[38] Johnson K L, Kendall K, Roberts A D. Surface energy and the contact of elastic solids. Proc. R. Soc. Lond. A, 1971: 324(1558): 301-313.

[39] Li J, Tong J, Hu B, Wang H, Mao C, Ma Y. Calibration of parameters of interaction between clayey black soil with different moisture content and soil-engaging component in northeast China. Transactions of the CSAE, 2019; 35(6): 130-140. (in Chinese)

[40] Wu T, Huang W F, Chen X S, Ma X, Han Z Q, Pan T. Calibration of discrete element model parameters for cohesive soil considering the cohesion between particles. J. South China Agric. Univ., 2017; 38: 93-98. (in Chinese) 